\section{Encapsulation Techniques for Delivery of Bioactive Compounds in Milk and Dairy Products- A Review}

\author{
Deepali Mohite ${ }^{1}$ and Roji B Waghmare ${ }^{2 *}$ \\ ${ }^{1}$ Department of Food Technology, Rayat Shikshan Sanstha's, Karmaveer \\ Bhaurao Patil College (Autonomous), Vashi, Navi Mumbai, India
}

${ }^{2}$ Food Science and Technology, School of Biotechnology and Bioinformatics, D Y Patil University, Navi Mumbai, India

\begin{abstract}
Encapsulation of food ingredients is one of the most important applications in food industry. The developing interest of consumers towards natural ingredients has resulted in the use of bioactive compounds in dairy applications. Encapsulation is an attractive technique to enhance the stability of bioactive compounds with controlled release. This review article provides an overview of various encapsulation techniques such as spray drying, extrusion method, emulsion, spray chilling, coacervation, cocrystallization and different encapsulated bioactive compounds which have been used for the fortification of dairy products. This review will help to give valuable insight that may be useful for commercialization of suitable encapsulated bioactive compounds in dairy industry.
\end{abstract}

Keywords: Bioactive compound; Cheese; Encapsulation; Fortification; Milk

\section{Introduction}

Presently, there has been a rising attention on human wellbeing, especially with intercessions through dietary sources. The nutraceuticals and functional foods market shows significant innovation to fulfil the consumer demand. In fact, people are looking for some novel and safer food ingredients that can not only simply give nutrients but also

*Corresponding author: Roji B Waghmare, Department of Food Science and Technology, School of Biotechnology \& Bioinformatics, D Y Patil University, Plot No. 50, Sector - 15, CBD Belapur, Navi Mumbai, 400614, Maharashtra, India, E-mail: rosewaghmare@gmail.com

Citation: Mohite D, Waghmare RB (2020) Encapsulation Techniques for Delivery of Bioactive Compounds in Milk and Dairy Products- A Review. J Dairy Res Tech 3: 017.

Received: May 29, 2020; Accepted: July 03, 2020; Published: July 10, 2020

Copyright: (c) 2020 Mohite D, et al. This is an open-access article distributed under the terms of the Creative Commons Attribution License, which permits unrestricted use, distribution, and reproduction in any medium, provided the original author and source are credited. benefit their health and secure their wellbeing. This has drawn attention of consumers for food bioactive compounds, nutraceuticals and functional foods. Several bioactive compounds are present in various foods such as vitamins, pigments, enzymes, flavours, essential fatty acids etc. However, these bioactive compounds are sensitive to degradation due to heat, light, oxygen and other stress conditions [1].

Since, several bioactive compounds are poorly soluble, mico/nanoencapsulation enhances the delivery of these poorly soluble bioactive compounds into functional food components [2]. It improves the physical stability \& bioactivity of these compounds in final food products and during processing. Encapsulations also protect bioactive compounds during digestion and enhance their uptake in gastrointestinal tract [3]. Further, encapsulation is used to prevent the reaction between bioactive compounds with other deteriorating components such as oxygen, light etc. [4,5].

Encapsulation is generally consisting of embedding one substance into another substance and preparing particles in the scale of nanometer, micrometer and millimeter [6]. Encapsulation has several applications in various sectors and its spontaneous growth has altered different areas of food sector such as processing, packaging, storage etc. Various techniques are available for the encapsulation of active compounds, however none of them can be considered as an all-inclusive material one. Encapsulation supports the delivery of the bioactive compounds and can have a controlled discharge at various time intervals. This technique helps to enhance the protection, safety and effectiveness of the compound [3]. In microencapsulation, the product has a size ranging between 1 to $1000 \mu \mathrm{m}$. However, nanoencapsulation should have a size and shape of the material below $1 \mu \mathrm{m}(1000 \mathrm{~nm})$. The reduced size of the particle to the nanoscale exposed more available active site on the surface of these delivery systems which provide benefits for their absorption within the digestive system of the body [4]. Figure 1 shows the factors which influence the encapsulation efficiency. The selection of encapsulation technique, wall material and processing parameters are equally responsible for the encapsulation efficiency [7].

Milk and dairy products play an important role in human diet since ancient times. Milk not only provides basic nutrition to the human body but also contains significant source of bioactive components. Recently, various studies have been conducted on the incorporation of bioactive compounds in milk and dairy products. As a result of this, dairy product manufacturer is introducing new products with specific nutrients or bioactive components [8]. Although several studies has been conducted on the encapsulation of bioactive compounds and its applications in milk and milk products with the commercialization of products has been made, the knowledge between the industry and academic should be exchanged. In the present review article, research based on encapsulation of bioactive compounds and its applications in milk and dairy products will be discussed. This review will help researchers to study the different bioactive compounds with its potential applications in milk and milk products. 


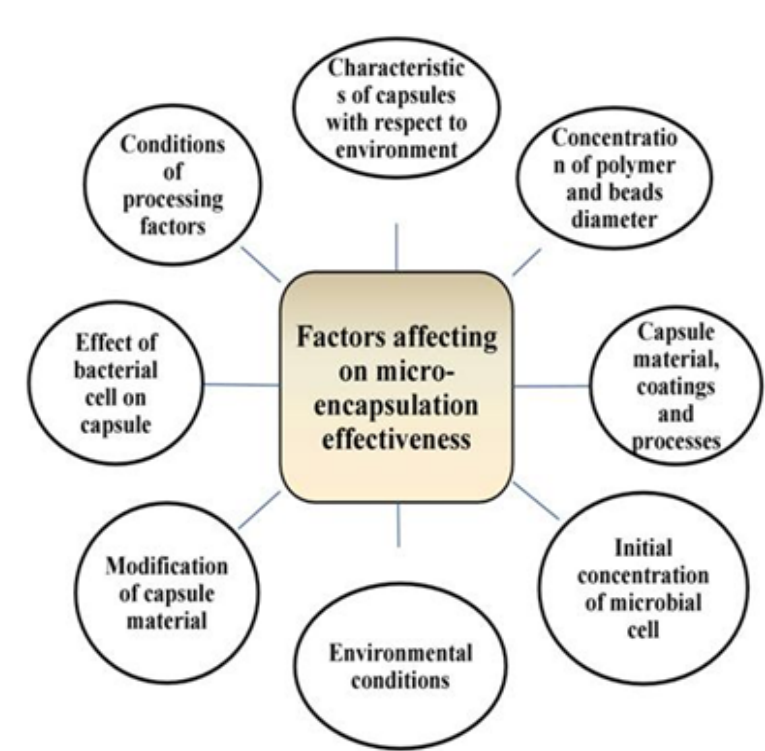

Figure 1: Factors affecting microencapsulation efficiency.

\section{Encapsulation Techniques}

Various encapsulation techniques have been employed for the encapsulation of bioactive compounds in dairy products. The main steps required for the encapsulation of these bioactive compounds are 1) development of wall over the encapsulated compound 2) prevention from unwanted leakage and 3) prevention from unwanted material. The encapsulation techniques involves spray drying, extrusion method, emulsion, spray chilling (or spray cooling), coacervation, cocrystallization etc. Table 1 shows the various encapsulation techniques used for the bioactive compounds for the applications in milk and dairy products.

\section{Spray drying}

Spray drying is a common encapsulation technique used on a large scale in the dairy sector. This technique is utilized to produce a high-quality and uniform particle size of less than $40 \mu \mathrm{m}$ [17] Different encapsulating agents used for spray drying are polysaccharides (maltodextrins, starches, gums, and corn syrups), lipids (monoglycerides, diglycerides, and stearic acid) and proteins (casein, gelatin, soy, milk serum) [7]. The mechanism of spray drying includes atomization of dissolved polymer in the continuous phase in the drying chamber. This encloses the core material particles resulting in the formation of capsules attained as a free-flowing dry powder. The main advantage of spray drying is a simple process which acquires uniform and small bead size. The disadvantage of spray drying is its high temperature which is unsuitable for the survival of microorganisms in the case of probiotic encapsulation [18]. The solid/oil/water emulsions were prepared by suspending spray-dried lactase powder in anhydrous milk fat which is added with sodium caseinate and lecithin emulsifier [19]. The prepared emulsion was able to encapsulate greater part of the spray-dried lactase powder. The encapsulated lactase was preserved after adding in milk and stayed dispersed while storage. The encapsulated lactase was discharged continuously in simulated digestions to hydrolyze lactose in milk. The mentioned study proved that the solid/oil/water emulsions are effective to include lactase in milk.

\section{Extrusion method}

Extrusion is one of the most common technique used to obtain bioactive capsules with hydrocolloids. The scale up is more difficult in this technique due to the slower formation of beads. The mechanism of the extrusion technique includes the preparation of a hydrocolloid solution and mixing the desired bioactive ingredient to the solution. This mixture is then suspended through an extruder in the form of droplets which are allowed to free-fall into a hardening solution or setting bath (in case of alginate, the gelling bath is $0.05-1.5 \mathrm{M}$ calcium chloride solution). For dripping various devices can be used such as pipette, syringe, spraying nozzle, jet cutter or atomizing disk. For industrial application Jet cutter is frequently used [20]. After dripping, the beads are immediately entrapped by the polymers leading to three-dimensional lattices that cross-links with calcium ions. The capsules formed using extrusion technique are large and of uniform particle size. The bead size ranges from 2 to $3 \mathrm{~mm}$ in diameter which is dependent on the distance between syringe and hardening solution, polymer type, viscosity, concentration and mainly diameter of the extruder orifice [21].

Thangaraj et al., [9] used extrusion technique for the encapsulation of vitamin $\mathrm{C}$ in flavoured milk. In this method, Sodium alginate solution was prepared and then L-Ascorbic acid was added to the solution. The prepared solution containing L-Ascorbic acid was dropped into calcium chloride solution. Calcium chloride used for hardening the vitamin-C microcapsules. The microcapsules were screened and washed with water. In another research encapsulation of $L$. $c a$ sei ATCC 393 cells were made using of extrusion method [15]. The diameter of the beads were $597.46 \pm 58.66 \mu \mathrm{m}$ and the viable cells count was $7.85 \pm 0.10 \log \mathrm{cfu}^{-1}$. The probiotic capsules produced by extrusion method provide more viability to the cells as compared to free cells under simulated gastrointestinal circumstances and storage period. Hence, more survival rate of probiotic Lactobacillus casei were found in the fermented milk production and during storage, with maintenance of the quality characteristics in the final product.

\section{Emulsion method}

The mechanism of emulsion technique is highly dependent on the accordance with discontinuous and continuous phases. A little portion of the aqueous phase containing an emulsifier (i.e., the discontinuous phase) is homogenized in a large portion of oil (i.e., the continuous phase) to form a water-in-oil emulsion. The water-soluble polymer (hydrophilic wall material) must be insolubilized to form minute gel particles within the oil phase (hydrophobic core material). The beads formed are obtained later by membrane filtration. Any surfactant, phospholipid or biopolymer can be used as emulsifiers. The vegetable oil, soy oil, corn salad oil can be used for the continuous phase depends on the type of supporting material used. A surfactant such as Sodium Lauryl Sulfate (SLS) can also be used to lower the surface tension in the coating matrix to prevent the size of the spheres. The emulsion technique is a complex process but harvest smaller beads and is easy to scale up [22]. In contrast to the extrusion encapsulation, emulsion has advantageous such as simple scale-up, less diameter capsules. Whereas, the large size range and shape, more cost of efficiency for the formulation of vegetable oil in emulsion are the major disadvantageous [23]. Fortification of dairy products can be done by liposome encapsulation technique by practicing oil and water based formulations. Vitamin D is effectively transmitted in oil based formulations. The studies proved that the vitamin $\mathrm{D}_{3}$ in emulsion forms was more stable than the powder form in cheese fortification [24]. 
Citation: Mohite D, Waghmare RB (2020) Encapsulation Techniques for Delivery of Bioactive Compounds in Milk and Dairy Products- A Review. J Dairy Res Tech 3: 017 .

- Page 3 of 9 •

\begin{tabular}{|c|c|c|c|c|c|}
\hline Technique of encapsulation & Bioactive compound & $\begin{array}{l}\text { Milk or dairy } \\
\text { product }\end{array}$ & Particle size & Major findings & Reference \\
\hline Extrusion technique & L-ascorbic acid & Flavoured milk & - & $\begin{array}{l}\quad \text { Larger stability up to a month } \\
\text { - } 95 \% \text { microencapsulation efficiency was achieved using 15:1 } \\
\text { as coating to core material } \\
\text { Retention of } 92 \mathrm{mg} \text { 1-ascorbic acid }\end{array}$ & [9] \\
\hline Liposomes method & Vitamin C & Buffalo milk & $200-1000 \mathrm{~nm}$ & $\begin{array}{l}\text { Prevent vitamin } \mathrm{C} \text { losses } \\
\text { Provided some stability to vitamin } \mathrm{C} \\
\end{array}$ & [10] \\
\hline Phase inversion method & Vitamin D3 & Milk & $31.43-36.66 \mathrm{~nm}$ & $\begin{array}{l}\text { - Ability to encapsulate high amounts of Vitamin D3 into } \\
\text { nano carriers } \\
\text { Encapsulation efficiency of lipid nano capsules were in the } \\
\text { range of } 93.25-98.81 \%\end{array}$ & [11] \\
\hline $\begin{array}{l}\text { Micro encapsulation with PGMS } \\
\text { (polyglycerol monostearate) }\end{array}$ & $\begin{array}{l}\text { ferric ammonium } \\
\text { sulfate }\end{array}$ & Milk & $2-5 \mu \mathrm{m}$ & $\begin{array}{l}\text { Highest efficiency of microencapsulation was } 75 \% \text { with } \\
5: 1: 30 \text { ratio }(\mathrm{w} / \mathrm{w} / \mathrm{v}) \text { as coating to core materials to distilled } \\
\text { water } \\
\text { - Iron release was } 12 \% \text { when stored at } 4{ }^{\circ} \mathrm{C} \text { for } 3 \text { days }\end{array}$ & [12] \\
\hline Micro encapsulation & Ferrous sulfate & Cheddar cheese & $\begin{array}{l}700-1,000 \mu \mathrm{m} \\
220-422 \mu \mathrm{m}\end{array}$ & $\begin{array}{l}\text { - } 66 \% \text { iron recovery for LMFS (large microencapsulated } \\
\text { ferrous sulfate) and 91.0\% iron recovery for SMFS (small } \\
\text { microencapsulated ferrous sulfate) } \\
\text { SMFS showed better results compared with LMFS for iron } \\
\text { retention and sensory evaluation }\end{array}$ & [13] \\
\hline Microencapsulation & $\begin{array}{l}\text { Lactobacillus bugari- } \\
\text { cus cells }\end{array}$ & $\begin{array}{l}\text { Frozen dairy } \\
\text { dessert }\end{array}$ & $>30 \mu \mathrm{m}$ & $\begin{array}{l}\text { - Encapsulated cells survived freezing better than non-capsu- } \\
\text { lated cells } \\
\text { - } 90 \% \text { cells survival was noted by encapsulation technique } \\
\text { Encapsulation had no interference in sensorial characteris- } \\
\text { tics }\end{array}$ & [14] \\
\hline Extrusion method & $\begin{array}{l}\text { Lactobacillus casei } \\
\text { ATCC } 393\end{array}$ & Fermented milk & $0.7 \mathrm{~mm}$ & $\begin{array}{l}\text { - Higher viability of encapsulated cells in gastrointestinal } \\
\text { conditions } \\
\text { - Alginate matrix has great potential as coating material of } \\
\text { probiotics }\end{array}$ & [15] \\
\hline Ultrasonic dispersion method & Curcumin & Milk & $212.3 \mathrm{~nm}$ & $\begin{array}{l}\text { The milk fat globule membrane (MFGM) liposomesshowed } \\
\text { higher encapsulation efficiency, smallerparticle size, higher } \\
\text { absolute value of } \zeta \text {-potential, andslower in vitro release }\end{array}$ & [16] \\
\hline
\end{tabular}

Table 1: Studies using different encapsulation techniques for the encapsulation of bioactive compounds and its application in milk and dairy products.

\section{Spray-chilling/spray-cooling}

Spray-chilling or spray-cooling is the technique generally used to create lipid-coated active agents to commonly encase flavours and allows constant release in wet mediums. The major difference between these two methods of spray chilling and spray cooling is the melting point of fats. For spray chilling temperature used is in the range of $34-42^{\circ} \mathrm{C}$, whereas, for spray cooling temperature is more [25]. These two methods are very similar to spray drying but the variations in the temperature of air for drying. Spray chilling method consists of bursting of molten wall material into finer particles through a nozzle into a drying chamber with dry ice at the temperature of $-50^{\circ} \mathrm{C}$. This causes a development of droplets coating a film. In case of spray cooling encapsulation, a molten crosslink, as the wall matter, attract the core materials and are spray cooled [26].

\section{Coacervation}

Coacervation is a simple and an inexpensive process which requires low temperatures or organic solvents. The coacervation process is the dissociation phase of a liquid phase into a polymer-rich phase (coacervate) and a polymer-poor phase. It consists of the dissociation phase of one or many hydrocolloids from the initial solution and ensuing deposition of the newly-constituted coacervate phase around the active element emulsified in the same reaction media [27]. Microcapsules produced by coacervation method increases controlled ability based on mechanical stress, temperature or sustained release. The main drawback of the coacervation method is that it performs only within narrow ranges of $\mathrm{pH}$, colloid concentrations and/or electrolyte concentrations [28].

\section{Co-crystallization}

Co-crystallization involves a mechanism in which active composites are immersed in the solutions containing large concentrations of carbohydrates. Crystallization of the carbohydrates starts with the decrease in temperature and due to over-saturation. The compound to be encapsulated gets entrapped in the crystals as they form [29]. Co-crystallization offers a cheap choice and is a flexible technique due to its simplicity and better stability. The downside of this approach is that it provides very low hygroscopic granular products and the heat labile core bioactive material may get degraded [30].

\section{Bioactive Compound}

\section{Vitamin}

The main aim of vitamin fortification in dairy products is primarily to attain the special nutritional needs of different ranges of populations. This can be achieved by preventing the risk of degradation of vitamins by applying suitable encapsulating methods with appropriate coating materials. Ascorbic acid (vitamin C) is an essential water-soluble micronutrient and has very important functions in the human body. The low level of Vitamin C content is found in milk and due to its heat lability, the major content of it is lost during heat treatment of milk. To achieve the fallibility regarding the instability of ascorbic acid during its addition to milk, microencapsulation has been 
Citation: Mohite D, Waghmare RB (2020) Encapsulation Techniques for Delivery of Bioactive Compounds in Milk and Dairy Products- A Review. J Dairy Res Tech 3: 017 .

proposed as a suitable approach $[8,31]$ proved that fortified milk products can be prepared with microencapsulated ascorbic acid and iron. In this study, the wall material used was Medium-Chain Triacylglycerol (MCT) which enclosed ferric ammonium sulfate and L-ascorbic acid; the highest efficiency of microencapsulation using 15:1 as coating to core material was reported to be $95.0 \%$. Similarly, Thangaraj et al., [9] developed flavoured milk sample encapsulated with vitamin-C by extrusion technique which resulted in a better-quality product and attained stability for about a month with the retained quantity of 92 $\mathrm{mg}$ of vitamin-C.

Sharma et al., [10] fortified raw, pasteurized and sterilized milk samples with encapsulated ascorbic acid as well as non-encapsulated ascorbic acid. The mean total Vitamin $\mathrm{C}$ content in each milk samples added with encapsulated ascorbic acid was 366.71, 345.80, and $210.74 \mathrm{mg} / \mathrm{l}$ and that for milk samples added with non-encapsulated ascorbic acid was $364.84,322.37$ and $203.21 \mathrm{mg} / 1$ respectively. The microencapsulation was successful to attain the stability at pasteurization temperature $63^{\circ} \mathrm{C}$ for 30 minutes whereas failed to achieve stability at sterilization temperature of $121^{\circ} \mathrm{C}$ for 15 minutes. At higher temperature, microencapsulation of vitamin $\mathrm{C}$ was not effective.

In the dairy industry, the milk fat portion is segregated from the skim milk portion to produce non-fat products leading to loss of fat-soluble vitamins such as A and D [24]. In accordance with the latest medical reports available, the maximum population throughout the universe is prone to vitamin D deficiency [32]. In order to overcome these drawbacks, the United States and Canada, declared a compulsory fortification of milk with vitamin D [8].

In the research study conducted by Leskauskaite et al., [33] proved that Vitamin D3 introduced dairy product shown no loss in Vitamin D3 during the processing. The main aim of this research was to fortify yoghurt and sour cream by vitamin D3 with the help of emulsion. The prepared emulsion was stabilized by whey protein and carboxymethyl cellulose. The idea behind the preparation of emulsion was to encapsulate vitamin D3 inside the dispersed oil phase. This protects the encapsulated compound against the degradation during processing, storage and during digestion from enzymes and acidity. Hence, the preparation of emulsion has significant impact on the protection of vitamin D3 degradation. Similarly Kiani et al., [11] worked on the encapsulation of vitamin D3 loaded lipid nanocapsules (LNC) by phase inversion treatment. Lipid-based nanocarriers are best for the conveyance of those compounds [34]. This was evident in this research where LNC proved the $90 \%$ efficient transportation of vitamin D3 in milk by phase inversion method [11]. The cheese was fortified with Vitamin D3 which was encapsulated into flaxseed oil emulsion formulations; the cheese was fortified successfully with $91 \%$ recovery level of Vitamin D3 in presence of lecithin [35].

\section{Mineral}

The fortification of dairy products with encapsulated mineral salts through different encapsulation techniques using various coating materials was initiated to preserve various physicochemical and organoleptic properties of the food matrix and to develop novel functional foods. Since the last 20 years, the focal point for researchers is to fortify dairy products with encapsulated minerals such as ferrous, calcium, zinc, and iron to prevent the fat oxidation, the off-flavor, the off-color, and sedimentation caused due to mineral fortification [8]. Controlled release of iron in fortified foods can be effectively achieved by microencapsulation. This enhances the bioavailability of iron and also prevents the undesirable sensory complications. Gupta et al., [36] developed iron microencapsules using four different encapsulation methods such as liposome, fatty acid esters, freeze-drying and emulsification methods for fortification of milk. In this study, microcapsules processed using the emulsification method showed the highest encapsulation efficiency whereas microcapsules processed using the fatty acid esters technique showed the lowest efficiency among all the methods. Again, in another study conducted by Abbasi et al., [37], similar observation was found for fatty acid esters encapsulation method. These researchers proved that this method is more effective, economical and feasible for microencapsulation of iron to incorporate in pasteurized milk than the liposome method. The encapsulation efficiency rate of fatty acid esters was $81 \%$ which was achieved using a Polyglycerol Monostearate (PGMS) / iron ratio of $15: 1$.

The microencapsulation of iron was studied by Kwak et al., [12], using Polyglycerol Monostearate (PGMS) as coating material and ferric ammonium sulfate as core material. This study showed $75 \%$ encapsulation efficiency with 5:1:30 ratio $(\mathrm{w} / \mathrm{w} / \mathrm{v})$ as coating to core materials to distilled water. In simulated intestinal fluid, the iron release elevated to $96 \%$ (pH8) from 12\% (pH5), after the 60 min incubation. Small microcapsules are preferred in the food matrix to prevent any textural changes such as gritty texture on the surface of milk. This was proved in the study of iron-fortified cheese [13]. Cheddar cheese was processed with large microencapsulated ferrous sulfate (LMFS; 700-1,000 $\mu \mathrm{m}$ in diameter) and small microencapsulated ferrous sulfate (SMFS; $220-422 \mu \mathrm{m}$ in diameter). The estimated result was that $91 \%$ iron recovery was observed for SMFS and only $66 \%$ iron recovery was observed for LMFS and also iron content showed an elevation from $0.030 \mathrm{mg}$ of $\mathrm{Fe} / \mathrm{g}$ in control cheddar cheese to 0.134 $\mathrm{mg}$ of $\mathrm{Fe} / \mathrm{g}$ of cheese in LMFS and $0.174 \mathrm{mg}$ of Fe/g of cheese in SMFS. Hence reducing the particle size of the microcapsules help to retain the iron content and preserve organoleptic properties. On the other hand, in the same study it was revealed that microencapsulation of ferrous sulfate failed to obscure the basic sensory attributes of iron.

\section{Probiotic}

The word probiotic is procured from Greek words which precisely means "for life" [38]. The word 'Probiotic' is defined by the Food and Agriculture Organization (FAO) of the United Nations and the World Health Organization (WHO) as "live micro-organisms that when administered in adequate amounts confer a health benefit on the host". Maximum probiotics in the food chain are incorporated in fermented milks and dairy products; as a matter of fact, dairy products are the vital transporter of probiotics available [39]. Survival of probiotic organisms in the intestine is most important as they are exposed to acid and bile salts for the multiplication in the colon [40]. It is very important that the encapsulated probiotic organisms should live and pass through the upper digestive tract with enough number of probiotic organisms to impart valuable effect in the intestine. Lactobacillus and Bifidobacterium species are commonly used in fermented milks because these species shows better resistance against adverse environment such as reduced $\mathrm{pH}$, hydrogen peroxide and molecular oxygen [41]. The strict food safety regulations implemented in different parts of the world have made the initiative for clinically based confirmation for approval of health claims of probiotics used in dairy products. It is difficult to maintain the stability of probiotic strains in 
Citation: Mohite D, Waghmare RB (2020) Encapsulation Techniques for Delivery of Bioactive Compounds in Milk and Dairy Products- A Review. J Dairy Res Tech 3: 017 .

a particular dairy product due to bacterial-food component interactions in the food matrix [42]. They have claimed benefits that control cholesterol levels, reduce the risk of intestinal infections, and promote lactose utilization in lactose intolerant material and anticarcinogenic activity [39]. The therapeutic level of probiotics in carrier food is $10^{6}$ $10^{8} \mathrm{CFU} / \mathrm{g}$ which is proved to be the requisite amount that needs to be consumed by humans for the beneficial probiotic effect and can be achieved by microencapsulation technique [43]. Microencapsulation of probiotic cultures in the food matrix has proved to be the best option to prevent the issues of survivability of probiotics [40]. The encapsulating biomaterials used to synthesize the coating membrane for probiotic encapsulation are alginate, carrageenan, gelatin, chitosan and cellulose acetate phthalate [7].

In the research done by Dimitrelloua, et al., [15] to encapsulate probiotic Lactobacillus casei ATCC 393 cells in Ca-alginate capsules by extrusion technique showed high survival rates during the fermented milk production with no loss in the sensorial characteristics in the final product. Alginate matrix showed high potential as a wall material for the encapsulation of probiotics. In a similar study, the sensorial properties were not affected by the addition of encapsulated polyphenolic compounds in alginate- inulin beads in the dairy dessert prepared from chokeberry [44]. Microencapsulation enhanced the survival of probiotic bacterial culture in the food matrix as well as gastrointestinal tract has been proved by Afzaal, et al., [43]. In this research, probiotic bacteria were encapsulated with sodium alginate and carrageenan. The encapsulated probiotic bacteria and free bacteria were added separately in yogurt. The survival rate of encapsulated probiotic bacteria was more than the free cells in in vitro gastrointestinal assay. The total cell counts of probiotic bacteria encapsulated with sodium alginate was $9.91 \mathrm{logs} \mathrm{CFU} / \mathrm{ml}$ and with carrageenan was $8.39 \log \mathrm{CFU} / \mathrm{ml}$. Encapsulated bacteria showed only $3 \log$ reduction in survival rate whereas non encapsulated bacteria showed 7 $\log$ reduction in survival rate. Hence, it was stated that encapsulation enhanced the viability of the probiotics in yogurt as well as gastrointestinal tract.

Viability of probiotics in ice-cream is challenging during production and storage due to the exposure of strains to stress caused by the acidity of the products, high osmotic pressure, freeze injury, and exposure to air [39]. This problem of probiotic stability was overcome by micro entrapment of Lactobacillus bulgaricus cells in calcium alginate beads which showed $90 \%$ survival of cells in the frozen dessert and also the entrapment effectiveness was enhanced by the addition of $6 \%$ glycerol [14]. Similarly, Bifidobacteria cells are sensitive to high acidity and hence its incorporation in yogurt is difficult. In the research done this issue was proved to be solved by encapsulating the Bifidobacterial cells in the carrageenan coating material which showed no loss in viable cells for about a month when stored at $4^{\circ} \mathrm{C}$. However, non-encapsulated cells showed a reduction of 78 and $70.5 \%$ in the cell population of Bifidobacterium longum B6 and B. longum ATCC 15708, respectively [45].

\section{Enzyme}

The microencapsulation technique has been an efficient technique to preserve and improve the nutritional and sensorial properties of foods by protecting the active compound. A most advanced microencapsulation technique is implemented in the dairy industry by the use of enzymes that are enclosed with their substrates for quick flavour production in dairy products [46]. The cheese quality is affected by the direct addition of enzymes in milk during cheese production which leads to a reduction of enzyme volume in whey. This problem of enzyme loss in whey can be improved by encapsulating enzymes in liposomes. Liposomes retained by the curd accelerate cheese ripening process. The reason for accelerated ripening in cheese is due to the breakdown of liposomes and release of encapsulated enzymes after removal of whey [47]. Similarly, Anjani et al., [48] studied the microencapsulation of enzymes for cheese ripening. These authors found that the flavour retention and even distribution of enzyme was enhanced by encapsulating flavourzyme in alginate or polylysine polymers followed by gelling in $0.1 \mathrm{M} \mathrm{CaCl}_{2}$. This helped in the achievement of $70 \%$ encapsulation efficiency. Gelling time was optimized for 10 minutes for hardening and to prevent the leakage of the encapsulated enzymes. In another study conducted by Kailasapathy et al., [49], flavourzyme enzyme was encapsulated in gellan, k-carrageenan and a High-Melting-Fat-Fraction of milk fat (HMFF) to reveal the impact of accelerated cheddar cheese ripening. In this study, it was reported that the k-carrageenan capsules showed a higher percentage rate of proteolysis of $56 \%$ in cheese as compared to gellan and HMFF which showed $48 \%$ and $39 \%$ proteolysis rate respectively.

In western countries, a wide area of the population contains an inadequate amount of lactase enzyme which breaks down lactose into glucose and galactose in their Gastrointestinal Tract (GI). After consumption of milk, lactase deficient people have to face many clinical symptoms like abdominal pain, watery diarrhoea, bloating, and cramping; hence the person facing these symptoms due to lack of lactase enzyme in the GI tract is called as 'lactose intolerant' patient. To overcome this problem lactase immobilization method was implemented but unfortunately it failed due to elevation in the sweetness of milk due to lactose hydrolysis in milk [50]. Lactose-free products may also have a loss in nutritional and sensorial properties of milk. Hence to eliminate these problems, microencapsulation has proved to be the most suitable technique. This is evident in the study performed by Zhong [51] where lactase was encapsulated in the form of zein-lactase into low-methoxyl sugar beet pectin cross-linked by $\mathrm{Ca} 2+$ including electrostatic, hydrophobic, hydrogen-bonding forces. The method was proved to be effective after 3 weeks of milk storage at $4{ }^{\circ} \mathrm{C}$ which resulted in 33.1 and $40.0 \%$ lactose hydrolysis in whole and skim milk respectively, by 50 units $/ \mathrm{mL}$ encapsulated lactase. The enzyme must be released slowly in the GI tract for digestion rather than during the storage of milk. This objective was achieved by Yun et al., [19] by encapsulating lactase by solid/oil/water emulsions as delivery systems which results in $75 \%$ encapsulation efficiency. This encapsulated lactase was delivered constantly while simulated digestions to hydrolyze lactose in milk better than free lactase.

\section{Antioxidants and phenolic compounds}

The demand and attention of consumers worldwide are increasing towards the healthier and functional foods that require novel technologies for introducing health benefit ingredients into the food matrix. These nutritional ingredients may degrade due to processing conditions and oxidation reactions. These bioactive compounds may also react with other food components in the food matrix which may degrade the food quality. Hence, encapsulation of antioxidant has potential to preserve and conserve the antioxidant compound. The fortification of low-fat cheese was done by Rashidinejad et al., [52] by incorporating catechin and epigallocatechin gallate (EGCG) 
Citation: Mohite D, Waghmare RB (2020) Encapsulation Techniques for Delivery of Bioactive Compounds in Milk and Dairy Products- A Review. J Dairy Res Tech 3: 017 .

which was nanoencapsulated in soy lecithin liposomes. This incorporation elevated total phenolic content in the cheese. However, no loss of polyphenols in whey was reported due to the nanoencapsulation technique which indicated the maximum retention in the cheese matrix with slow-release in GI conditions. In another study performed by Zabodalova et al., [53], milk drink was fortified with Liposomal beta-carotene obtained by dehydration/rehydration method. The study resulted that liposomal beta-carotene can be used for formulating functional dairy products as it maintained stability during storage at 4 $\pm 2^{\circ} \mathrm{C}$ within 15 days.

The curcumin is a natural phenolic compound has a strong antioxidant, anti-carcinogenic and anti-inflammatory properties. Due to its low solubility of curcumin in water, the milk matrix plays a suitable medium for the encapsulation of curcumin as milk contains casein micelle which is amphiphilic. This property of the curcumin is implemented in the research study performed by Landim Neves et al., [54] which proved the efficiency of skim milk for encapsulation of curcumin. The encapsulation of curcumin was by pilot scale spray dryer. As stability of curcumin antioxidant activity was achieved by encapsulation, the encapsulation confirmed to be the appropriate method for the protection of antioxidant. Jin et al., [16] compared the stability of the 2 curcumin liposomes prepared with milk fat globule membrane (MFGM) phospholipids and soybean lecithins. The retention rate of encapsulated liposomal curcumin was greater than free curcumin. The stability of both the liposomal curcumin was equal for different $\mathrm{pH}$ conditions. However, MFGM phospholipids showed more stability than soybean lecithins under conditions of temperature, oxygen, and relative humidity. $74 \%$ encapsulation efficiency was achieved for curcumin enclosed in liposomes prepared with MFGM phospholipids. The MFGM liposomes also showed an average particle size of $212.3 \mathrm{~nm}$, higher absolute value of $\zeta$-potential of -48.60 $\mathrm{mV}$, and slower in vitro release.

\section{Omega}

Healthy foods enriched with bioactive are been proving to be consumers need to prevent health diseases. Omega-3 fatty acids are unsaturated fatty acids that are important in the human diet in the form of Alpha-Linolenic Acid (ALA), Eicosapentaenoic Acid (EPA) and Docosahexaenoic Acids (DHA) have potential to develop health and prevent diseases. The human body is unable to synthesize EPA and DHA directly so they are produced by metabolic reactions of ALA through food and hence there is an extreme need for enriching foods with omega-3 fatty acids [55]. The omega 3 fatty acids are prone to oxidation hence can degrade the nutritional and sensorial quality of food. The addition of encapsulated omega-3 fatty acids can overcome these problems. In one of the experimentations done by Stratulat, et al. [35] on cheddar cheese, flaxseed oil was used in the form of emulsion to encapsulate vitamin D3. In this study, calcium caseinate was used to stabilize the emulsion. Improved stability was observed by the addition of calcium caseinate and showed more resistant against lipid oxidation. In another research, Augustin et al., [56] used buttermilk as an encapsulant for the formation of omega- 3 oil emulsion and powder. Alone whole buttermilk or with combination in glucose syrup enhanced the oxidative stability of both emulsions and powders. Whole buttermilk powder was also proved to be a potential encapsulant for the delivery of omega- 3 fatty acids as compared to high heat skim milk buttermilk powder.

\section{Conclusions and Future Perspectives}

Encapsulation of bioactive compounds and its incorporation in dairy products such as milk, cheese, yogurt, ice cream etc provides distinct advantageous since it improves the stability and protect the bioactive compounds. Comparatively less literature has been available on the encapsulation of bioactive compounds and on its application in dairy. Further studies are required on the different types of bioactive compounds and its applications in encapsulation for dairy products. Based on this review article, it is necessary to bring researchers from various streams such as food technology, engineering, nanotechnology and biotechnology to establish an encouraging future for the use of encapsulated bioactive compounds in dairy products.

\section{References}

1. Assadpour E, Jafari SM (2019) Advances in Spray-Drying Encapsulation of Food Bioactive Ingredients: From Microcapsules to Nanocapsules. Annu Rev Food Sci Technol 10: 103-131.

2. Bazana MT, Codevilla CF, de Menezes CR (2019) Nanoencapsulation of bioactive compounds: challenges and perspectives. Current Opinion in Food Science 26: 47:56.

3. Zanetti M, Carniel TK, Dalcanton F, Anjos RS, Riella HG, et al. (2018) Use of encapsulated natural compounds as antimicrobial additives in food packaging: A brief review. Trends in Food Science \& Technology 81: 5160 .

4. Suganya V, Anuradha V (2017) Microencapsulation and Nanoencapsulation: A Review. International Journal of Pharmaceutical and Clinical Research 9: 233-239.

5. Nedovic V, Kalusevica A, Manojlovic V, Levic S, Bugarski B (2011) An overview of encapsulation technologies for food applications. In Procedia Food Science 1: 1806-1815.

6. Burgain J, Gaiani C, Linder M, Scher J (2011) Encapsulation of probiotic living cells: From laboratory scale to industrial applications. Journal of Food Engineering, 104: 467-483.

7. Kavitakea D, Kandasamya S, Devi PB, Shetty PH (2018) Recent developments on encapsulation of lactic acid bacteria as potential starter culture in fermented foods - A review. Food Bioscience 21: 34-44.

8. Kwak H-S, Mijan MA, Ganesan P (2014) Application of Nanomaterials, Nano- and Microencapsulation to Milk and dairy products. Nano- and Microencapsulation for Foods (Chapter 11), John Wiley \& Sons, Inc., USA.

9. Thangaraj SM, Seethalakshmi M (2015) Application of Microencapsulation Technology for the Production of Vitamin-C Fortified Flavoured Milk. Advances in Dairy Research 3: 1-4.

10. Sharma R, Lal D (2005) Fortification of milk with microencapsulated vitamin $\mathrm{C}$ and its thermal stability. Journal of Food Science and Technology 42: 191-194.

11. Kiani MFA, Ghasemi SM (2016) Production of novel vitamin D3 loaded lipid nanocapsules for food fortification. International Journal of Food Properties 20: 2466-2476.

12. Kwak HS, Yang KM, Ahn J (2003) Microencapsulated Iron for Milk Fortification. J Agric Food Chem 51: 7770-7774.

13. Arce A, Ustunol Z (2018) Effect of microencapsulated ferrous sulfate particle size on Cheddar cheese composition and quality. J Dairy Sci 101: 6814-6822.

14. Sheu TY, Marshall RT, Heymann H (1993) Improving Survival of Cultural Bacteria in frozen desserts by microentrapment. Journal of Dairy Science 76: 1902-1907. 
Citation: Mohite D, Waghmare RB (2020) Encapsulation Techniques for Delivery of Bioactive Compounds in Milk and Dairy Products- A Review. J Dairy Res Tech 3: 017 .

15. Dimitrelloua D, Kandylis P, Lević S, Petrović T, Ivanović S, et al. (2019) Encapsulation of Lactobacillus casei ATCC 393 in alginate capsules for probiotic fermented milk production. LWT 116: 108501.

16. Jin H-H, Lu Q, Jiang J-G (2016) Curcumin liposomes prepared with milk fat globule Curcumin liposomes prepared with milk fat globule American Dairy Science Association 1-11.

17. Zuidam NJ, Heinrich J (2009) Encapsulation of aroma. In: Zuidam NJ, et al. (Eds.) Encapsulation Technologies for Food Active Ingredients and Food Processing. Springer, Dordrecht, The Netherlands, Pg no: 127-160.

18. McClements DJ, Decker EA (2007) United States Patent No. US 20070104866A1.

19. Zhang Y, Zhong Q (2018) Freeze-dried capsules prepared from emulsions with encapsulated lactase as a potential delivery system to control lactose hydrolysis in milk. Food Chem 241: 397-402.

20. Prüsse U, Bilancetti L, Bucko M, Bugarski B, Bukowski J, et al. (2008) Comparison of different technologies for alginate beads production. Chem Pap 62: 364-74.

21. Solanki HK, Pawar DD, Shah DA, Prajapati VD, Jani GK, et al. (2013) Development of microencapsulation delivery system for longterm preservation of probiotics as biotherapeutics agent. Biomed Res Int 2013: 620719 .

22. Lakkis JM (2007) Encapsulation and Controlled Release Technologies in Food Systems. John Wiley \& Sons, Inc., USA.

23. Kailasapathy K (2006) Survival of free and encapsulated probiotic bacteria and their effect on the sensory properties of yogurt. LWT Food Science and Technology 39:1221-1227.

24. Zahedirad M, Asadzadeh S, Nikooyeh B, Neyestani TR, Khorshidian N, et al. (2019) Fortification aspects of vitamin D in dairy products: A review study. International Dairy Journal 94: 53-64.

25. Gouin S (2004) Microencapulation: industrial appraisal of existing technologies and trends. Trends Food Sci Technol 15: 330-347.

26. Jafari SM (2017) Nanoencapsulation of Food Bioactive Ingredients Principles and Applications. Elsevier, UK.

27. Aloys H, Korma SA, Alice TM, Chantal N, Ali AH, et al. (2016) Microencapsulation by Complex Coacervation: Methods, Techniques, Benefits, and Applications - A Review. American Journal of Food Science and Nutrition Research 3: 188-192.

28. Mishra M (2018) Encyclopedia of Polymer Applications. CRC Press, Taylor \& Francis, USA.

29. Champagne CP, Fustier P (2007) Microencapsulation for delivery of probiotics and other ingredients in functional dairy products. Functional Dairy Products 2: 404-426.

30. Pegg RB, Shahidi F (2007) Encapsulation, Stabilization, and Controlled Release of Food Ingredients and Bioactives in Handbook of Preservation. CRC Press, Taylor \& Francis, USA.

31. Lee JB, Ahn J, Kwak HS (2003) Microencapsulated Ascorbic Acid for Milk Fortification. Arch Pharm Res 26: 575-580.

32. Mauryaa VK, Bashirb K, Aggarwal M (2019) Vitamin D microencapsulation and fortification: Trends and technologies. Journal of Steroid Biochemistry and Molecular Biology 196: 105489.

33. Leskauskaite D, Jasutiene I, Malinauskyte E, Kersiene M, Matusevicius P (2015) Fortification of dairy products with vitamin D3. International Journal of dairy Technology 69: 177-183.

34. Rezaei A, Fathi M, Jafari SM (2019) Nanoencapsulation of hydrophobic and low-soluble food bioactive compounds within different nanocarriers. Food Hydrocolloids 88: 146-162.
35. Stratulat I, Britten M, Salmieri S, Fustier P, St-Gelais D, et al. (2015) Enrichment of cheese with vitamin D3 and vegetable omega-3. Journal of Functional Foods 13: 300-307.

36. Gupta C, Chawla P, Arora S (2015) Development and evaluation of iron microencapsules for milk fortification. CyTA - Journal of Food 13: 116123.

37. Azari SAS (2011). Efficiency of novel iron microencapsulation techniques: fortification of milk. International Journal of Food Science and Technology 46: 1927-1933.

38. Vivek (2013) Use of encapsulated probiotics in dairy based foods. International Journal of Food, Agriculture and Veterinary Sciences 188-199.

39. Chen MJ, Chen K-N (2007) Applications of Probiotic Encapsulation in Dairy Products. Encapsulation and Controlled Release Technologies in Food Systems (Chapter 4), John Wiley \& Sons, Inc., USA.

40. Doraisamy KA, Karthikeyan N, Elango A (2018). Microencapsulation Of Probiotics In Functional Dairy Products Development. International journal of Advance Research in Science and Engineering 7: 1-14.

41. Iravani S, Korbekandi H, Mirmohammadi SV (2015) Technology and potential applications of probiotic encapsulation in fermented milk products. J Food Sci Technol 52: 4679-4696

42. Kasipathy K, Champagne CP (2011) Trends in the microencapsulation of probiotics for application in dairy products. Supplement to Agro FOOD industry hi-tech 22: 25-27.

43. Afzaal M, Khan AU, Saeed F, Ahmed A, Ahmad MH, et al. (2019) Functional exploration of free and encapsulated probiotic bacteria in yogurt and simulated gastrointestinal conditions. Food Science and Nutrition 7: 3931-3940.

44. Vlaseva R, Ivanova M, Denev P, Petkova NT (2014) Preparation of dairy dessert with addition of encapsulated biologically active substances. AgriFood Sciences Processes and Technologies.

45. Adhikari K, Mustapha A, Grun IU, Fernando L (2000) Viability of Microencapsulated Bifidobacteria in Set Yogurt During Refrigerated Storage. J Dairy Sci 83: 1946- 1951.

46. el Soda M, Pannell L, Olson N (1989) Microencapsulated enzyme systems for the acceleration of cheese ripening. J Microencapsul 6: 319-326.

47. Kirby CJ, Brooker BE, Law BA (1987) Accelerated ripening of cheese using liposome encapsulated enzyme. International journal of food science and technology 22: 355-375.

48. Anjani K, Kailasapathy K, Phillips M (2007) Microencapsulation of enzymes for potential application in acceleration of cheese ripening. International Dairy Journal 7: 79-86.

49. Kailasapathy K, Lam SH (2005) Application of encapsulated enzymes to accelerate cheese ripening. International Dairy Journal 15: 929-939.

50. Lianger D (2018) Encapsulation of lactase in dispersible biopolymer particles as a potential delivery system to control lactose hydrolysis in milk Graduate School at Trace: Tennessee Research and Creative Exchange.

51. Dong L, Zhong Q (2019) Dispersible Biopolymer Particles Loaded with Lactase as a Potential Delivery System To Control Lactose Hydrolysis in Milk. Journal of Agricultural and Food Chemistry 67: 6559-6568.

52. Rashidinejad A, Birch EJ, Sun-Waterhouse D, Everett D (2016) Effect of liposomal encapsulation on the recovery and antioxidant properties of green tea catechins incorporated into a hard low-fat cheese following in vitro simulated gastrointestinal digestion. Food and Bioproducts Processing 100: 238-245.

53. Zabodalova L, Ishchenko T, Skvortcova N, Baranenko D, Chernjavskij V (2014) Liposomal beta-carotene as a functional additive in dairy products. Agronomy Research 12: 825-834. 

Tech 3: 017.

- Page 8 of 9 •

54. Neves MIL, Desobry-Banon S, Perrone IT, Desobry S, Petit J (2019). Encapsulation of curcumin in milk powders by spray-drying: Physicochemistry, rehydration properties, and stability during storage. Powder technology 345: 601-607.

55. Feizollahi E, Hadian Z, Honarvar Z (2018) Food Fortification with Omega-3 Fatty Acids; Microencapsulation as an Addition Method. Current Nutrition \& Food Science 18: 90-103.
56. Augustin MA, Bhail S, Cheng LJ, Sen Z, Øiseth S, et al. (2014) Use of whole buttermilk for microencapsulation of omega-3 oils. Journal of functional foods 19: 859-867. 


\section{If \\ HramL}

Advances In Industrial Biotechnology | ISSN: 2639-5665

Advances In Microbiology Research | ISSN: 2689-694X

Archives Of Surgery And Surgical Education | ISSN: 2689-3126

Archives Of Urology

Archives Of Zoological Studies | ISSN: 2640-7779

Current Trends Medical And Biological Engineering

International Journal Of Case Reports And Therapeutic Studies | ISSN: 2689-310X

Journal Of Addiction \& Addictive Disorders | ISSN: 2578-7276

Journal Of Agronomy \& Agricultural Science | ISSN: 2689-8292

Journal Of AIDS Clinical Research \& STDs | ISSN: 2572-7370

Journal Of Alcoholism Drug Abuse \& Substance Dependence | ISSN: 2572-9594

Journal Of Allergy Disorders \& Therapy | ISSN: 2470-749X

Journal Of Alternative Complementary \& Integrative Medicine | ISSN: 2470-7562

Journal Of Alzheimers \& Neurodegenerative Diseases | ISSN: 2572-9608

Journal Of Anesthesia \& Clinical Care | ISSN: 2378-8879

Journal Of Angiology \& Vascular Surgery | ISSN: 2572-7397

Journal Of Animal Research \& Veterinary Science | ISSN: 2639-3751

Journal Of Aquaculture \& Fisheries | ISSN: 2576-5523

Journal Of Atmospheric \& Earth Sciences | ISSN: 2689-8780

Journal Of Biotech Research \& Biochemistry

Journal Of Brain \& Neuroscience Research

Journal Of Cancer Biology \& Treatment | ISSN: 2470-7546

Journal Of Cardiology Study \& Research | ISSN: 2640-768X

Journal Of Cell Biology \& Cell Metabolism | ISSN: 2381-1943

Journal Of Clinical Dermatology \& Therapy | ISSN: 2378-8771

Journal Of Clinical Immunology \& Immunotherapy | ISSN: 2378-8844

Journal Of Clinical Studies \& Medical Case Reports | ISSN: 2378-8801

Journal Of Community Medicine \& Public Health Care | ISSN: 2381-1978

Journal Of Cytology \& Tissue Biology | ISSN: 2378-9107

Journal Of Dairy Research \& Technology | ISSN: 2688-9315

Journal Of Dentistry Oral Health \& Cosmesis | ISSN: 2473-6783

Journal Of Diabetes \& Metabolic Disorders | ISSN: 2381-201X

Journal Of Emergency Medicine Trauma \& Surgical Care | ISSN: 2378-8798

Journal Of Environmental Science Current Research | ISSN: 2643-5020

Journal Of Food Science \& Nutrition | ISSN: 2470-1076

Journal Of Forensic Legal \& Investigative Sciences | ISSN: 2473-733X

Journal Of Gastroenterology \& Hepatology Research | ISSN: 2574-2566
Journal Of Genetics \& Genomic Sciences | ISSN: 2574-2485

Journal Of Gerontology \& Geriatric Medicine | ISSN: 2381-8662

Journal Of Hematology Blood Transfusion \& Disorders | ISSN: 2572-2999

Journal Of Hospice \& Palliative Medical Care

Journal Of Human Endocrinology | ISSN: 2572-9640

Journal Of Infectious \& Non Infectious Diseases | ISSN: 2381-8654

Journal Of Internal Medicine \& Primary Healthcare | ISSN: 2574-2493

Journal Of Light \& Laser Current Trends

Journal Of Medicine Study \& Research | ISSN: 2639-5657

Journal Of Modern Chemical Sciences

Journal Of Nanotechnology Nanomedicine \& Nanobiotechnology | ISSN: 2381-2044 Journal Of Neonatology \& Clinical Pediatrics | ISSN: 2378-878X

Journal Of Nephrology \& Renal Therapy | ISSN: 2473-7313

Journal Of Non Invasive Vascular Investigation | ISSN: 2572-7400

Journal Of Nuclear Medicine Radiology \& Radiation Therapy | ISSN: 2572-7419

Journal Of Obesity \& Weight Loss | ISSN: 2473-7372

Journal Of Ophthalmology \& Clinical Research | ISSN: 2378-8887

Journal Of Orthopedic Research \& Physiotherapy | ISSN: 2381-2052

Journal Of Otolaryngology Head \& Neck Surgery | ISSN: 2573-010X

Journal Of Pathology Clinical \& Medical Research

Journal Of Pharmacology Pharmaceutics \& Pharmacovigilance | ISSN: 2639-5649

Journal Of Physical Medicine Rehabilitation \& Disabilities | ISSN: 2381-8670

Journal Of Plant Science Current Research | ISSN: 2639-3743

Journal Of Practical \& Professional Nursing | ISSN: 2639-5681

Journal Of Protein Research \& Bioinformatics

Journal Of Psychiatry Depression \& Anxiety | ISSN: 2573-0150

Journal Of Pulmonary Medicine \& Respiratory Research | ISSN: 2573-0177

Journal Of Reproductive Medicine Gynaecology \& Obstetrics | ISSN: 2574-2574

Journal Of Stem Cells Research Development \& Therapy | ISSN: 2381-2060

Journal Of Surgery Current Trends \& Innovations | ISSN: 2578-7284

Journal Of Toxicology Current Research | ISSN: 2639-3735

Journal Of Translational Science And Research

Journal Of Vaccines Research \& Vaccination | ISSN: 2573-0193

Journal Of Virology \& Antivirals

Sports Medicine And Injury Care Journal | ISSN: 2689-8829

Trends In Anatomy \& Physiology | ISSN: 2640-7752

Submit Your Manuscript: https://www.heraldopenaccess.us/submit-manuscript 